\title{
Negative Option Contracts and Consumer Switching Costs*
}

\author{
OWEN R. PHILLIPS \\ University of Wyoming \\ Laramie, Wyoming
}

\section{Introduction}

A negative option contract is an agreement by which a buyer accepts a flow of goods from a vendor until the buyer notifies the vendor otherwise.' In the finance literature [10], a negative option contract would probably be referred to as a negative call option. The contract gives the holder the right to refuse buying the good or service, but the holder does not have to exercise this right. The trade literature argues that negative option contracts were pioneered by the Book-of-the-Month Club more than 60 years ago [2]. Book Club members agree to accept, with the right of refusal, a selected book every month until they opt out of the Club. A similar method of marketing is common in the recording industry through tape and compact disk clubs. It is estimated that 10 million consumers in the U.S. belong to a negative option club of some sort [8]. These contracts are legally binding in all states if the consumer signs an agreement that starts the flow of deliveries. Book, recording, and video clubs have thrived with the added feature of "prenotification" for the next unit of delivery. This itself is a negative option. Just before the next delivery the consumer is given the option to refuse the good, usually by mailing a postcard. If the vendor is not notified, delivery is forthcoming. Prenotification gives the consumer control over the bundle of goods ultimately received. Consumers can self-select components of the bundle and the bundle size. ${ }^{2}$

Certain negative option plans have come under public scrutiny. Recently Tele-Communications Inc. (TCI) attempted to sell its cable subscribers the Encore channel as a negative option contract. All subscribers were to receive the channel unless TCI was notified otherwise, and all subscribers would pay a monthly charge for the service unless TCI was notified otherwise to

*Helpful comments have been received from Fred Sterbenz and Lih-Jau Wang. I am especially grateful for the insights provided by an anonymous referee. This material is based upon work supported by the National Science Foundation under grant RII-8610680 and the College of Business, University of Wyoming. Any opinions, findings, and conclusions or recommendations expressed in this paper are those of the author and do not necessarily reflect the views of the funding agencies.

1. Contract provisions may allow the vendor to stop the flow of goods by notifying the buyer. The vendor may cease the flow without notification if the buyer fails to meet stipulations of the agreement, e.g., untimely payment. Likewise buyers may refuse the flow without notification if parts of the agreement are not satisfied.

2. Without prenotification in a negative option contract, a positive option agreement would give a consumer relatively more control over the make-up of a product package. Prenotification, which generally allows for rejection or substitution of the forthcoming item, arguably provides the consumer as much freedom of choice over components of the bundle as advance ordering. However, buyers complain that prenotification pressures them to make decisions that would be deferred otherwise, or not made at all [20]. The trade journals cited above suggest this pressure is a major reason for increased sales under negative option contracts. 
discontinue the service. The first negative option was unacceptable to most consumer advocates. State attorneys in Florida, Iowa, Pennsylvania, Texas, and Washington, to name just a few of the public opponents, brought suit against TCI. They argued the service must be initiated as a positive option; consumers must explicitly give permission to begin the service flow. Eventually TCI capitulated to this protest. The channel was supplied only upon request, but service continued thereafter as a negative option [16].

A less visible controversy has arisen over local Bell telephone companies providing inside wire maintenance as a negative option. For a small charge per month, usually less than $\$ 1.00$, the Bell company agrees to service and repair telephone wiring within the customer's premises. These maintenance contracts were initiated as both a negative option in some regions and a positive option in others. Interestingly, under a negative option, for example in the Rocky Mountain region, about $75 \%$ of the customers did not deny the service and so received it. In the Northwest where a positive option was required to begin the service, about $75 \%$ of the telephone customers did not respond and so did not receive it. Marketers attribute this kind of behavior to consumer inertia, but there are other explanations. One being the existence of close substitutes to the service in both regional markets. Assuming there are, the full cost of responding has the same impact in both markets.

Negative option contracts for telephone wire maintenance in the Rocky Mountain states prompted a civil antitrust suit. Gordon C. Ham, et al. vs. Mountain Bell (Colorado case No. 87CV23146) brought a class action suit against Mountain Bell. The 1987 complaint argued that Mountain Bell primarily through negative option contracts had attempted to monopolize the telephone wire maintenance market in violation of section II of the Sherman Act and Colorado antitrust laws. Mountain Bell had approximately $75 \%$ of this "market". New entrants were blocked from the market because of the already existing contracts, which had no explicit termination date. The complaint continued to argue that the telephone company had intended to erect a barrier to entry with its negative option agreements, and that entry would be much easier and maintenance contract prices lower without the negative option. This case has been settled out of court, and some compensation is being paid to the certified class [5]. Mountain Bell, though, continues to employ the negative option as a marketing device for other services. Recently they have asked customers to take one free month of call waiting service. If accepted, the service is billed to the customer after the one month until Mountain Bell is notified otherwise.

For those agreements like the book clubs an important feature of a negative option contract is the legal right to return an unacceptable unit of the product flow. The right has a price, because there is at least a transaction cost of return that buyers must pay. This is a switching cost that is paid when consumers choose to change or reduce the components of the bundle supplied by the seller over some period of time. A second switching cost arises if the buyer decides to end the product flow. Now the buyer seeks to exit the contract with the vendor. These costs are usually transactional, but may include contract penalties. They represent a barrier to entry to potential sellers, because consumers will be reluctant to pay these switching costs if, at best, they view the product of the entrant as a close substitute to that currently provided. Both types of switching costs are studied in this paper.

In a two good world this paper begins with a model of consumer equilibrium behavior when sales of good $X$ are made through a negative option contract. In section II the model shows that when it comes to the buyer selecting and the seller supplying components of a product bundle, a negative option agreement can be Pareto superior to a positive option contract. Hence negative option contracts appeal to both the buyer and seller and thus explains why this method of market- 
ing is pervasive. Next, in sections III and IV of this paper, there is a discussion of how a negative option can raise the costs of potential entrants. The argument is that if customers pay an exit or switching cost to dissolve the contract with the incumbent firm, a two-part tariff is forced upon the potential customers of the entrant. The incumbent may have control over this switching cost, so it can be endogenous. These sections show that a profit maximizing entrant will pay part of this cost for the consumer if a switch is made. Section $V$ concludes the paper with a discussion on the public policy of negative option contracts.

\section{Negative Options and the Product Bundle}

The consumer in this model agrees to accept units of a good under either a negative or positive option contract. The utility of these contracts is compared. The total quantity purchased by the consumer is not explicitly decided by either the positive or negative option contract, because the consumer may return the good at some cost under the negative option, or not request some units if the contract has a positive option. Specifically, there are two goods $X$ and $Y$, where $Y$ is a composite good, and $X$ is sold under a negative or positive option agreement. The negative option contract is patterned after the contracts in a book or recording club. The consumer agrees to take delivery of $X_{S}$ units (which may be specified by the buyer) with the option of returning the delivered item. The explicit return or switching cost may be quite low, because many negative option plans notify by mail the item is on the way and will be delivered unless the vendor is notified otherwise by mail.

The model's notation is now introduced:

$P_{Y} \equiv$ price of the composite good $Y$.

$P_{X} \equiv$ price of $\operatorname{good} X$.

$M \equiv$ income of consumer.

$X_{S} \equiv$ quantity of good $X$ delivered under the negative option contract.

$X_{R} \equiv$ quantity of good $X$ returned under the negative option contract.

$X_{T} \equiv X_{S}-X_{R}$; quantity of good $X$ consumed.

$P_{R} \equiv$ switching cost or price of returning one unit of good $X$. This amount is equivalent to the cost of placing an order under a positive option contract.

The negative option contract specifies that the consumer is sent $X_{S}$ units with the option of returning any item. The contract may specify that the consumer purchase some minimum number of items, but this feature of the agreement is not modeled. If the consumer chooses not to purchase any $X$ then total return costs are $P_{R} X_{S}$, and the consumer's income is reduced to $M-P_{R} X_{S}$; total $Y$ purchases are $\left(M-P_{R} X_{S}\right) / P_{Y}$. Thus even if no units of $X$ are consumed the return costs in a negative option contract affect the $Y$ intercept of the consumer's budget line. As mentioned, the out-of-pocket return cost can be quite low, but the full cost of switching $\left(P_{R}\right)$ can be much larger if opportunity costs of return are high. ${ }^{3}$ As the model is further explained, it becomes evident that sellers under the negative option have some incentive to keep $P_{R}$ low.

Return costs also impact the marginal price of good $Y$. In a negative agreement the price of $Y$ is not simply $P_{Y}$. In order to consume an additional unit of $Y$ while remaining on the budget

3. Book and recording clubs are aware that switching between items in the flow of goods sent is "most annoying" to customers. The full cost of switching may be large relative to the out-of-pocket expense [20]. 
constraint, the consumer must return some amount of $X$ given by $P_{Y} / P_{X}$. The full price of $Y$ is therefore $P_{Y}+P_{R}\left(P_{Y} / P_{X}\right)=P_{Y}\left[1+\left(P_{R} / P_{X}\right)\right]>P_{Y}$. This price of good $Y$ is written into the following utility maximizing problem.

When the contract is in place the consumer's choice variables are returns, $X_{R}$, and the amount of the composite good $Y$. The optimization problem is, therefore,

$$
\begin{aligned}
& \operatorname{Max}_{X_{R}, Y} U\left[X_{T}\left(X_{R}\right), Y\right] \\
& \text { s.t. } \quad M=P_{X} X_{T}+P_{R} X_{R}+P_{Y}\left[1+\left(P_{R} / P_{X}\right)\right] Y, \quad \text { and } \\
& X_{R}+X_{T}=X_{S} .
\end{aligned}
$$

The second constraint restricts attention to purchases for which $X_{T} \leq X_{S}$. Consumption of good $X$ is less than or equal to the number of units delivered. It is possible that $X_{T}>X_{S}$. This changes the relative prices of the two goods $X$ and $Y$, and puts a kink in the budget line. This kink is discussed in more detail below. As the objective is written, the second constraint can be substituted into the first and the Lagrangian is

$$
\operatorname{Max}_{\lambda, X_{R}, Y} L=U\left[X_{T}\left(X_{R}\right), Y\right]+\lambda\left\{M-P_{X}\left(X_{S}-X_{R}\right)-P_{R} X_{R}-P_{Y}\left[1+\left(P_{R} / P_{X}\right)\right] Y\right\} .
$$

Ignoring $\partial L / \partial \lambda$, necessary first order conditions are

$$
\begin{aligned}
\partial L / \partial X_{R} & =\left(\partial U / \partial_{T}\right)\left(d X_{T} / d X_{R}\right)+\lambda P_{X}-\lambda P_{R}=0 \\
\partial L / \partial Y & =\partial U / \partial Y-\lambda P_{Y}\left[1+\left(P_{R} / P_{X}\right)\right]=0
\end{aligned}
$$

This is a problem in which equilibrium conditions on $X_{T}$ can be found even though $X_{T}$ is not a direct choice variable. From the second constraint in (1), an increase in $X_{R}$ by one unit reduces $X_{T}$ by one unit. Hence $\partial X_{T} / \partial X_{R}=-1$, and the above first order conditions lead to the conclusion that in equilibrium and for $P_{X}>P_{R}$ :

$$
\left(\partial U / \partial X_{T}\right) /(\partial U / \partial Y)=\left(P_{X}-P_{R}\right) /\left\{P_{Y}\left[1+\left(P_{R} / P_{X}\right)\right]\right\} .
$$

The slope of the budget line for a negative option contract is the right side of (3). Compared to a standard set up for which the ratio on the right is $P_{X} / P_{Y}$, a negative option arrangement has decreased the price of $X$ and increased the price of $Y$. Figure 1 illustrates the consumer's budget line. ${ }^{4}$

The other identified budget line in Figure 1 arises from a positive option contract. In contrast to the negative option, the consumer must place an order with the vendor each time the consumer wishes to take delivery. It is assumed that the cost of placing an order is the same as the cost of rejecting one; it is $P_{R}$. There are no returns in a positive option scenario, so the consumer purchases $X_{T}$ units of the good. The consumer's optimization problem is

$$
\begin{aligned}
& \operatorname{Max} U\left(X_{T}, Y\right) \\
& \text { s.t. } \quad M=\left(P_{X}+P_{R}\right) X_{T}+P_{Y} Y .
\end{aligned}
$$

4. Figure 1 shows on the vertical interest that $M / P_{Y}\left[1+\left(P_{R} / P_{X}\right)\right]<\left(M-P_{R} X_{S}\right) / P_{Y}$. This assumes $M /\left(P_{X}+P_{R}\right)$ $>X_{S}$, which need not be true. 


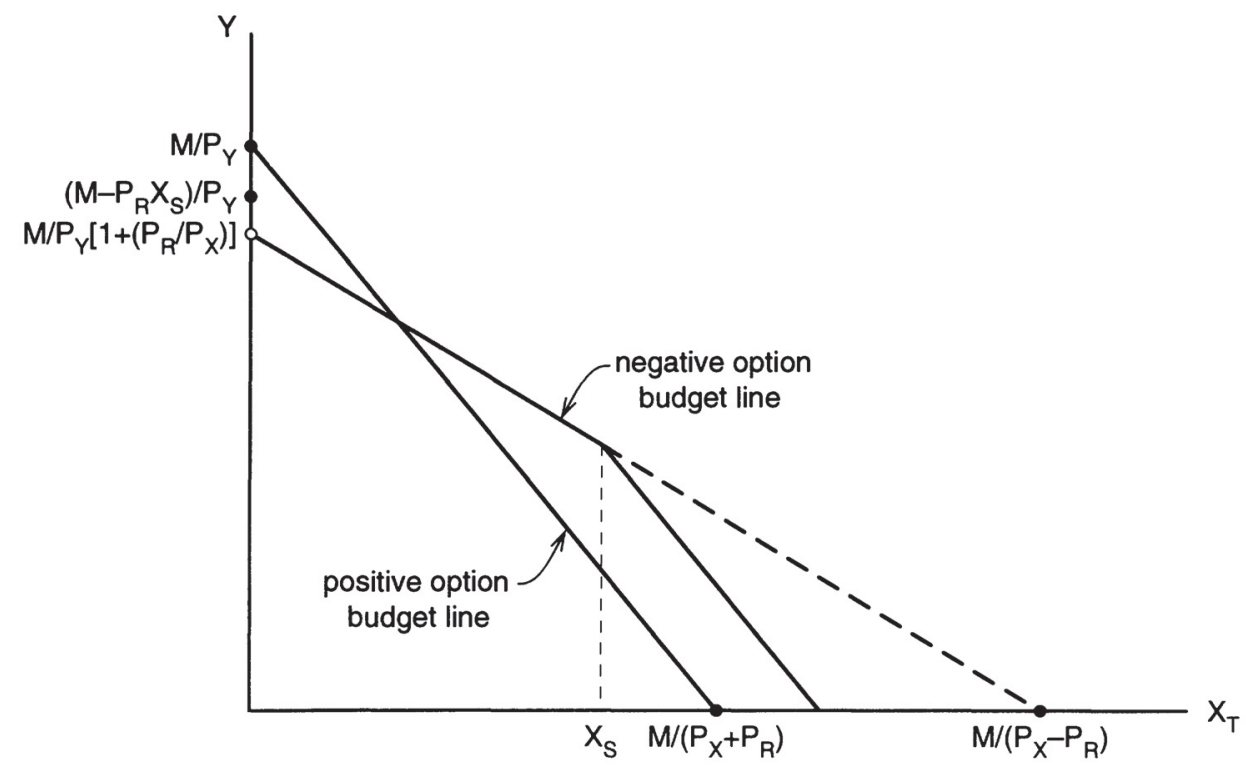

Figure 1. Negative and Positive Option Contract Budget Lines

Solving the first order conditions yields the equilibrium condition

$$
\left(\partial U / \partial X_{T}\right) /(\partial U / \partial Y)=\left(P_{X}+P_{R}\right) / P_{Y} .
$$

The full price of consuming a unit of $X$ under a positive option is $P_{X}+P_{R} .^{5}$

The kink in the negative option budget line now can be explained more fully. If the buyer should consume more of good $X$ than is sent by the vendor, i.e., $X_{T}>X_{S}$ under the negative option agreement, then it is assumed that additional units must be bought under some sort of positive option arrangement. For example, when a consumer's total purchases of compact discs or books exceeds the units supplied through a club membership, the buyer must then order additional units from the vendor or purchase elsewhere at the full price $P_{X}+P_{R}$. The effective price of $Y$ at $X_{S}=X_{T}$ therefore falls to $P_{Y}$, its level under the positive option agreement. At quantity $X_{S}$ shown in Figure 1 the slope of the negative option budget line becomes identical to the slope of the positive option budget line. The intercept on the $X_{T}$ axis is the ratio of income to a weighted average of prices $\left(P_{X}+P_{R}\right)$ and $P_{X}$.

Figure 1 suggests that a positive option contract will usually place the consumer on a lower level of utility than a negative option contract. This is because the perception of $P_{R}$ is different under the two delivery plans. Under a positive option when an order must be placed, $P_{R}$ becomes part of the full price of the good. Under a negative option the return price $P_{R}$ is the contractual price of a guarantee, exercised upon delivery of an unsatisfactory good. It is not part of the posted price; it is the price of a well-defined promise of service. This service is attached to each delivered item. Since the consumer views $P_{R}$ as a contingent claim price on each unit of $X$, the price $P_{X}$

5. The referee has pointed out that a positive option contract could be thought of as a special case of the negative option model. For a positive option agreement $X_{S}=0$. The return price $P_{R}$ is still the price of returns, but returns are negative where negative returns are interpreted as orders. In (1) there is the constraint $X_{R}+X_{T}=X_{S}$. In the positive option model this constraint becomes $X_{T}-X_{R}=0$, or $X_{T}=X_{R}$. Also, since $X_{S}=0$ the full price of good $Y$ is simply $P_{Y}$. Hence the model in (3) is a special case of (1). 
is discounted by the switching $\operatorname{cost} P_{R}$. Negative option contracts, compared to a positive option, are a more efficient means by which to accept or reject pieces of a product flow.

The producer under either contract agreement has not changed $P_{X}$. Nevertheless, sales can be (and probably are) greater under a negative option plan, because the rotation of the budget line for a tiny $P_{R}$ can benefit all but the smallest buyer. Therefore, it appears to the vendor that demand has increased, and profits rise. But Figure 1 shows that not every consumer benefits from a negative option contract. Small buyers could be moved to a lower indifference curve. A vendor can guarantee that every customer is made better off or not harmed by giving them a choice between a negative or positive option agreement. ${ }^{6}$ Providing the choice would unambiguously increase vendor sales, and consumers as a group would benefit. Hence negative option contracts are (weakly) Pareto superior to positive option contracts. If policy makers and consumer advocates desire that no consumer is harmed by a negative option plan they must insist on vendors giving buyers a choice between a positive or negative option plan. With no choice the return cost should be kept relatively low.

Marketers explaining the profitability of negative option contracts tend to describe a consumer who is "too lazy" to return an unwanted item. For whatever reason, the transaction's costs to the buyer are sufficiently high that he or she decides to keep the marginal unit. A consumer "too lazy" therefore would be interpreted in the model as a buyer having high return costs $P_{R}$. But this suggests negative option plans have limited appeal. Figure 1 shows that as $P_{R}$ increases, the negative option budget line slides downward, along the positive option budget line. With a high $P_{R}$ the appeal of a negative option plan is restricted to relatively large buyers of $X$. The model provides a better explanation for why returns under a negative option plan are likely to be low or nonexistent. Consumers can have wide ranges in $P_{R}$ and possess a wide variety of marginal rates of substitution; even so, they will optimize at the kink in the negative option budget line. It is at this point that returns are exactly zero.

\section{Negative Options and Raising Rival's Cost}

Nearly all contracts, negative option or otherwise, impose a cost of exit. In a negative option agreement suppose the consumer must pay some switching cost, say $K$, for discontinuing the flow of services with the current vendor. The switching cost could include a stiff penalty; and in any case the opportunity cost of exit may be high. In the provision of long distance telephone services, the carriers AT\&T, MCI, and Sprint have in addition to the notification cost, a switching cost imposed on the consumer by the carrier and the local telephone exchange. As another example, many bank services are offered under a negative option agreement. Lines of credit in particular are provided and the connected charges paid by the customer until the agreement is dissolved. The cost of switching to new bank can involve substantial transaction costs associated with developing new agreements and lender relationships. Paul Klemperer [11; 13] discusses a number of other cases for which switching costs exist and may be high. Switching costs entail forfeiting the promise of future price discounts, and/or additional services for those customers loyal to the incumbent vendor. Caminal and Matutes [6] discuss the strategic creation of coupons and price discounts as switching costs for the customers of two rival sellers.?

6. Recently the Book-of-the-Month Club has started this practice [20].

7. In both Klemperer papers $[11 ; 13]$ switching costs are shown to make duopoly markets less competitive. Their presence makes demand less elastic, allowing duopolists to raise price. Caminal and Matutes [6] let duopolists choose 
Klemperer [12] models how exogenous switching costs can completely forestall entry. In the analysis presented below switching costs are endogenous and entry is not necessarily blocked. Nevertheless, exiting costs for the consumer raise the cost of entry for potential vendors and damage their profitability. The entrant has in effect a two-part tariff imposed upon itself by the incumbent seller. The exiting cost acts as the fixed part of the tariff. Unfortunately for the entrant, even though the entrant's customer must pay this cost, the entrant does not collect the revenue. Therefore, with regard to the entrant's profit function, it is as if costs to the entrant have been raised by the incumbent seller. ${ }^{8}$

Krattenmaker and Salop [14] present a number of case studies by which one firm raises the costs of rivals in order to enhance its own profits. Many of these examples involve a firm writing an exclusionary contract with a low-cost supplier that subsequently requires a rival to seek higher cost inputs. As such, this is a violation of the Sherman Act. Generalizing from their studies, Krattenmaker and Salop argue $[14 ; 250-251]$ that raising rival's cost violates antitrust laws if two conditions are met: (1) the action of a firm unambiguously raises a competitor's costs, and (2) the incumbent firm is able to raise its price, and profits as a consequence of the action. It is shown below that both of these conditions can be satisfied for negative option contracts. Similar to an exclusionary contract written between firms with a vertical relation, the negative option contract is viewed here as an exclusionary agreement with the final buyer.

The problem faced by the potential entrant is illustrated in Figure 2. The exit cost to the customer, caused by switching from the incumbent to the new vendor, is $K$. Independent of $K$, the entrant may charge a start-up fee (which is part of the total switching cost) to the new customer. This is shown as $F>0$ in the figure, although $F \lesseqgtr 0$ is possible, and it will be shown below that the profit maximizing entrant will use $F$ to pay some of the $K$ switching costs for the customer, hence it will be the case that $F<0$. The incumbent charges $P_{I}$ for each unit sold, so the expenditure function is $P_{I} X$ to a buyer doing business with the incumbent. Switching to the entrant entails a one-time payment of $K+F$ as shown in Figure 2. The entrant's price is $P_{E}$; therefore the expenditure function for consumers who buy from the entrant is $(K+F)+P_{E} X$.

Consumer demand is modeled in a fashion similar to Leland and Meyer [15] and Faulhaber and Panzar [9]. There is a continuum of consumer types indexed by $\theta, 0 \leq \theta \leq 1$. The number of consumers of type $\theta$ is given by the continuous function $g(\theta)$. For each buyer type $\theta$, there is the demand function $D\left(P_{E} ; \theta\right)$. Demand is differentiable in $P_{E}$ and $\theta$. Also the demands for different $\theta$ types do not cross. Thus $\partial D / \partial P_{E}<0$, and at each $\theta, \partial D / \partial \theta>0$. For each buyer type demand is downward sloping, and across buyer types demand is increasing.

Figure 2 shows that there exists a unique $\underline{\theta}, 0<\underline{\theta}<1$, that describes the consumer type indifferent about switching. This marginal consumer type is a function of $P_{E}, F, P_{I}$, and $K$. The entrant only has choice variables $P_{E}$ and $F$, with the latter two variables controlled by the incumbent. For the entrant's profit maximization problem, $P_{I}$ and $K$ therefore will be treated as

between future price discounts or coupons as ways to create switching costs for regular customers. In their model precommitments to lower future prices are more profitable than the issue of coupons.

8. Aghien and Bolton [3] model exiting costs in a contract with this same perspective. Most of their results are generated with one buyer negotiating with one seller over the price of one unit and the exit cost. More general versions of the model have more than one buyer, but buyer demand is still at most one unit. These authors conclude that the buyer and seller negotiate a contract to optimally extract rents from a potential entrant. Even so, entry is not completely blocked. Rasmusen, Ramseyer, and Whitey [17] show that a duopolist can gain by writing exclusionary contracts without exit costs. There are $N$ buyers with identical demand functions, and the profitability of exclusion depends on economics of scale. Tirole [18] provides a survey of Aghien and Bolton [3] and the earlier literature on contracts as barriers to entry. 


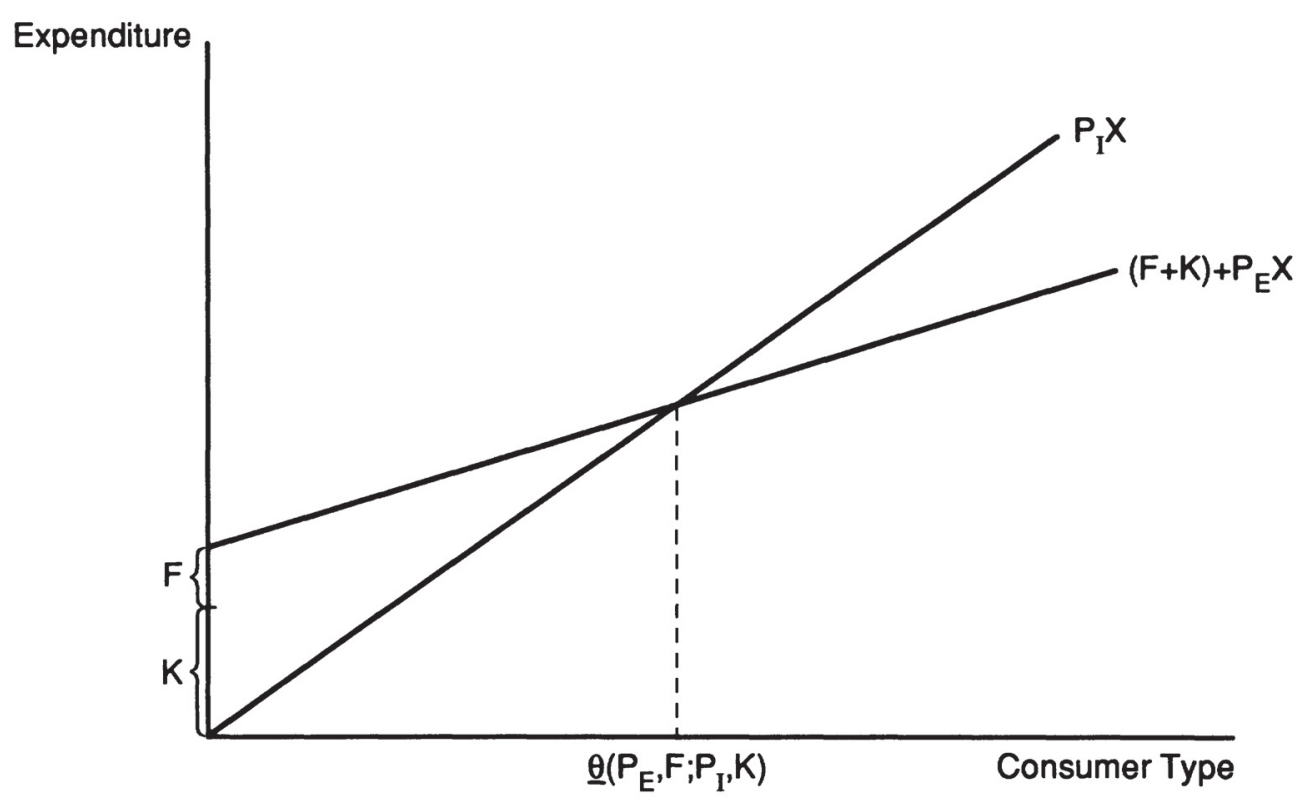

Figure 2. The Entrant's Pricing Problem

exogenous variables. Hence the marginal consumer type to the entrant is functionally described as $\underline{\theta}=\underline{\theta}\left(P_{E}, F ; P_{I}, K\right)$, and it is easily seen from Figure 2 that $\partial \underline{\theta} / \partial P_{E}>0$ and $\partial \underline{\theta} / \partial F>0$.

The profit function of the entrant is taken to be continuous and differentiable. The objective is expressed as

$$
\operatorname{Max}_{P_{E}, F} \pi_{E}=\int_{\underline{\theta}}^{1}\left[\left(P_{E}-C\right) D\left(P_{E} ; \theta\right)-F\right] g(\theta) d \theta,
$$

where $C$ is the constant marginal cost of production. Here $F$ is treated as if it is a fixed payment to customers, but the profit maximizing sign of $F$ has not yet been determined. The necessary first order conditions for profit maximization are

$$
\begin{aligned}
\partial \pi_{E} / \partial P_{E}= & \int_{\underline{\theta}}^{1}\left[D\left(P_{E} ; \theta\right)+\left(P_{E}-C\right)\left(\partial D / \partial P_{E}\right)\right] g(\theta) d \theta \\
& -\left(\partial \underline{\theta} / \partial P_{E}\right)\left[\left(P_{E}-C\right) D\left(P_{E} ; \underline{\theta}\right)-F\right] g(\underline{\theta}) \leq 0 \\
P_{E} \geq & 0 ; \quad P_{E}\left(\partial \pi_{E} / \partial P_{E}\right)=0,
\end{aligned}
$$

and

$$
\begin{aligned}
\partial \pi_{E} / \partial F & \left.=\int_{\underline{\theta}}^{1}-g(\theta) d \theta-(\partial \underline{\theta}) / \partial F\right)\left[\left(P_{E}-C\right) D\left(P_{E} ; \underline{\theta}\right)-F\right] g(\underline{\theta}) \leq 0 \\
F & \geq-K ; F\left(\partial \pi_{E} / \partial F\right)=0 .
\end{aligned}
$$

The Kuhn-Tucker restrictions in (7), allow nonpositive values for $F$; however, the entrant is kept from paying an amount more than the consumer's exit cost. It is assumed that when inequalities $\partial \pi / \partial P_{E}$ and $\partial \pi / \partial F$ are met with equality they are continuous functions in $P_{E}$ and $F$.

It can be shown that $F<0$ for the profit maximizing entrant by letting $F$ approach 0 and then checking the sign of (7). The assumption is that profits are maximized at $F=0$, but if at 
this point condition (7) is strictly negative, the assumption is contradicted and the entrant should decrease $F$ to increase profits. The inequality in (7) can be reduced by substituting from (6). For $F=0$ it is necessarily true for $(6)$ that

$$
\begin{aligned}
& {\left[1 /\left(\partial \underline{\theta} / \partial P_{E}\right)\right] \int_{\underline{\theta}}^{1}\left[D\left(P_{E} ; \theta\right)+\left(P_{E}-C\right)\left(\partial D / \partial P_{E}\right)\right] g(\theta) d \theta} \\
& \quad=\left[\left(P_{E}-C\right) D\left(P_{E} ; \underline{\theta}\right)\right] g(\underline{\theta}) .
\end{aligned}
$$

Condition (6) must be met with equality and more specifically $P_{E}-C>0$ or the firm has no means by which to generate positive revenue or profit. This is the standard uniform pricing condition. Leland and Meyer [15] and Faulhaber and Panzar [9] have generally shown $\boldsymbol{P}_{E}$ $>C$ at the profit maximizing point for $F \geq 0$. Substituting the left hand expression for $\left[\left(P_{E}-C\right) D\left(P_{E} ; \underline{\theta}\right)\right] g(\underline{\theta})$ from (8) into (7), condition (7) becomes

$$
\int_{\underline{\theta}}^{1}\left\{-1-\left[(\partial \underline{\theta} / \partial F) /\left(\partial \underline{\theta} / P_{E}\right)\right]\left[D\left(P_{E} ; \theta\right)+\left(P_{E}-C\right)\left(\partial D / \partial P_{E}\right)\right]\right\} g(\theta) d \theta<0 .
$$

The expression $D\left(P_{E} ; \theta\right)+\left(P_{E}-C\right)\left(\partial D / \partial P_{E}\right)$ is marginal profit from $P_{E}$ and is positive by (8). Thus the entire expression is negative. At $F=0$, the slope of the profit function is negative with respect to $F$ and therefore $F$ should be decreased. If $\underline{\theta} \neq 1$, i.e., the entrant operates at some level in the market, the profit maximizing rival pays at least part of the exit cost, along with discounting $P_{E}$ relative to the incumbent.

A prominent example of an entrant exhibiting a willingness to pay the switching costs of a new customer comes from the provision of long distance telephone service. MCI and Sprint have intensely lobbied customers to switch from AT\&T. They frequently offer to pay all out-ofpocket expenses connected with the transfer of service. These switching costs have raised the cost of entry. With more structure to the analytics, the next section shows that a profit maximizing incumbent seller has the incentive to set and maintain positive switching costs. There is a precise relation between the switching costs installed by the incumbent and the amount paid by the entrant. As the switching costs rise the entrant will pay more to attract customers.

\section{Linear Demand and Uniform Density}

This section of the paper borrows heavily from the models on spatial pricing as described for example in Beckmann [4] or Capozza and Van Order [7]. Suppose that the density of buyer types $\theta$ is uniform on the $[0,1]$ interval and demand for either the incumbent firm $(i=I)$ or the entrant $(i=E)$ has the linear form $D\left(P_{i}\right)=1-P_{i}+\theta$. Without a second firm in the market, the incumbent (I) services the entire market, so $P_{I}<1$, and remains so even after entry. If the entrant wants any share of the market it must set $P_{E}<P_{I}<1$. Ignoring marginal costs and the number of buyers at each point on the uniform interval, the entrant's profit objective is

$$
\underset{P_{E}, F}{\operatorname{Max}} \pi=\int_{\underline{\theta}}^{1}\left[P_{E}\left(1-P_{E}+\theta\right)+F\right] d \theta .
$$

As in the more general presentation $0 \leq \underline{\theta} \leq 1$. Those customers who decide to buy from the entrant $(\theta \geq \underline{\theta})$, must pay a switching (or exit) fee, $K$. It is also the case that the entrant can set a two-part tariff, where the one time entry fee is $F$; thus the full switching cost to the consumer 
is $K+F$. Even though the profit function in (10) is written as if $F$ is revenue to the entrant, it is shown below that $F$ is negative and that $K$ and $F$ have an inverse relation. The marginal consumer $\underline{\theta}$ is indifferent about buying from the incumbent or the entrant. This marginal buyer exists where $P_{I}\left(1-P_{I}+\underline{\theta}\right)=P_{E}\left(1-P_{E}+\underline{\theta}\right)+F+K$. Hence $\underline{\theta}$ can be written as the ratio:

$$
\underline{\theta}=\left[\left(P_{I}^{2}-P_{E}^{2}\right)-\left(P_{I}-P_{E}\right)+F+K\right] /\left(P_{I}-P_{E}\right) .
$$

The optimizing entrant seeks to maximize (10). Necessary first order conditions are

$$
\begin{aligned}
\partial \pi / \partial P_{E} & =\left[(1 / 2)\left(3-\underline{\theta}^{2}\right)\right]+\left[\left(-2 P_{E}+P_{E}^{2}-F\right)\left(\partial \underline{\theta} / \partial P_{E}\right)\right]-2 P_{E}(1-\underline{\theta})-\underline{\theta}=0 \\
\partial \pi / \partial F & =\left[\left(-2 P_{E}+P_{E}^{2}-F\right)(\partial \underline{\theta} / \partial F)\right]+(1-\underline{\theta})=0 .
\end{aligned}
$$

Solving for $\left(-2 P_{E}+P_{E}^{2}-F\right)$ in equation (13) and substituting into (12) yields $P_{E}=(3-\underline{\theta}) / 4$. Since $\underline{\theta}$ is bound between 0 and 1 , the profit maximizing price for the entrant is restricted to values between $1 / 2$ and 3/4. Closed form solutions for $P_{E}$ and $F$ require much algebra and provide little insight. But with these bounds on the optimal $P_{E}$, the profit maximizing $F$ is always negative. Note that $\partial \underline{\theta} / \partial F=1 /\left(P_{I}-P_{E}\right)$. Substituting this and also using the ratio for $\underline{\theta}$ from equation (11), $\partial \pi / \partial F$ reduces to

$$
F=P_{E}\left(P_{E}-4\right)+\left\{\left[P_{I}\left(2-P_{I}\right) / 2\right]-K / 2\right\}
$$

The first term, $P_{E}\left(P_{E}-4\right)$, is always negative given $1 / 2 \leq P_{E} \leq 3 / 4$, and is monotonically decreasing in $P_{E}$. The largest value it can take is therefore $-39 / 16$. The braced term ( \{\}$)$ in the solution reaches its largest value at $K=0$ and $P_{I}=1$. If $K$ is allowed to approach zero then the expression takes a value of $1 / 2$. Hence, for all possible values that the profit maximizing value $P_{E}$ can take, $F$ is negative whenever $K \geq 0$.

It is noteworthy the $\partial F / \partial K=-1 / 2<0$. As the switching or exit cost increases, the entrant sets $F$ lower. Higher switching costs impose a greater barrier to entry on the potential entrant. If $K$ is endogenous and the incumbent has some control over the exit cost, perhaps in the way the negative option contract is structured, then the incumbent has control over the cost of entry for potential rivals. And, it can be inferred that as the rival reduces $F$ to entice buyers away from the incumbent, the incumbent will raise the exit fee $K$. The potential entrant faces a barrier to entry that becomes higher as the entrant attempts to overcome it.

Negative option contracts are therefore an exclusionary measure. Through such contracting with buyers the incumbent raises the cost of potential rivals. Referring back to the public policy arguments against raising a rival's cost, negative option contracts fail the first test Krattenmaker and Salop [14] use to judge the legality of vertical contracts. A negative option damages competition in the market by raising the cost of entry. The second test suggested by Krattenmaker and Salop reviews prices and profits of the incumbent. If prices and/or profits rise, this completes the argument that the practice is a violation of antitrust law.

For this linear model, it can be shown that profits of the incumbent increase when there are exit costs, and that if exit costs can be set by the incumbent they will be positive. The profit objective of the incumbent, given that the entire market is served and $\theta<\underline{\theta}$ consumers buy from the incumbent, is written as

$$
\operatorname{Max}_{P_{l}, K} \pi_{I}=\int_{0}^{\underline{\theta}} P_{I}\left(1-P_{I}+\theta\right) d \theta+\int_{\underline{\theta}}^{1} K d \theta .
$$


Here, switching costs $K$ are explicitly endogenous. The incumbent chooses $P_{I}$ and $K$ so that $\theta>\underline{\theta}$ consumers switch to the entrant, and those who choose the entrant pay the exit fee $K$ to the incumbent. Necessary first order conditions are

$$
\begin{aligned}
\partial \pi / \partial P_{I} & =\left(\partial \underline{\theta} / \partial P_{I}\right)\left(1-P_{I}+\underline{\theta}\right)+\underline{\theta}\left[1-2 P_{I}+(\underline{\theta} / 2)\right]-K\left(\partial \underline{\theta} / \partial P_{I}\right)=0 \\
\partial \pi / \partial K & =P_{I}(\partial \underline{\theta} / \partial K)\left(1-P_{I}+\underline{\theta}\right)+(1-\underline{\theta})-K(\partial \underline{\theta} / \partial K)=0 .
\end{aligned}
$$

Dividing (17) by $\partial \underline{\theta} / \partial K$, where the partial derivative $\partial \underline{\theta} / \partial K=1 /\left(P_{I}-P_{E}\right)$, an implicit solution for $K$ is

$$
K=(1 / 2)\left[P_{I}\left(1-P_{I}\right)+P_{I} \underline{\theta}+\left(P_{I}-P_{E}\right)-F\right]>0 .
$$

Since $P_{E}<P_{I}<1$, the expression is positive. The same inverse relation between $K$ and $F$ observed in (12) for the entrant setting $F$ exists in (18) for the incumbent setting $K$. The incumbent will set a positive switching cost to maximize profits. Since $K$ could have been zero, profits are greater than those earned without a switching fee. Even in the more general formulation of section III, the incumbent can always set $K=0$. By the Le Châtelier principle, profits for a maximizer cannot be reduced by the capability to charge a switching fee. Thus incumbent vendors are able to raise profits through a positive exit cost, and the second test Krattenmaker and Salop [14] suggest as a way to distinguish legal from illegal vertical contracts points toward a violation of public policy. In this linear model a negative option contract fails both tests that separate socially desirable from undesirable contracting practices.

\section{Discussion}

Policy makers have had a difficult time accepting negative option contracts as a legal marketing strategy. Many of these programs have been associated with direct mail campaigns that are notorious for fine print and the omission of "details" about shipping and handling charges, return policies, and minimum quantities required. The Federal Trade Commission, although voting to permit the use of negative option contracts by marketers, has issued detailed guidelines about the content of negative option contracts. ${ }^{9}$ With respect to book and recording clubs, prenotification of shipment by the vendor is a strict requirement in these contracts. Other prominent features of the guidelines require vendors to make it plain to the consumer what the costs of exit are before the contract is put into place. In some contracts the fine print has made it difficult for consumers to stop delivery. The Book-of-the-Month Club has paid substantial fines for omitting crucial details about exit from (or fulfilling) the contract in a newspaper offer [1]. On one level this paper has shown that negative option contracts have Pareto efficiency advantages over positive option arrangements. They enhance consumer utility, because the option of return has value to a consumer independent of the product's price. In contrast, the cost of ordering under a positive option is viewed as part of the product's full price.

On a second level, the danger of negative options is that an exclusionary contract between the vendor and buyer exists. And just as contracting in any vertical relationship can cause barriers to entry in a market, so can a negative option contract. Analytically the exit or switching costs

9. See Section 425 of Federal Trade Commission Regulations [19]. 
a consumer must pay cause a profit maximizing entrant to cover some of these expenses. When switching costs between vendors is endogenous, the incumbent raises the cost of a potential entrant. The presence of the barrier is evidenced by the willingness of an entrant to pay at least part of the buyer's switching cost, and its height could be measured by the amount paid by the entrant. This amount increases as the exit fee set by the incumbent increases. As in Ham vs. Mountain Bell public policy must be aware that negative option contracts are a strategy by which to raise a rival's cost.

\section{References}

1. Advertising Age, September 18, 1978, 88.

2. — , October 11, 1984, 46-47.

3. Aghien, Philippe and Patrick Bolton, "Contracts as Barriers to Entry." American Economic Review, June 1987, $388-401$.

4. Beckmann, Martin, "Spatial Price Policies Revisited." Bell Journal of Economics, Autumn 1976, 619-30.

5. BOC Week, November 30, 1987.

6. Caminal, Ramon and Carmen Matutes, "Endogenous Switching Costs in a Duopoly Model." International Journal of Industrial Organization, 1990, 353-73.

7. Capozza, Dennis and Robert Van Order, "A Generalized Model of Spatial Competition." American Economic Review, December 1978, 896-908.

8. Direct Marketing, November 1991, 60-62.

9. Faulhaber, Gerald and John Panzar. "Optimal Two-Part Tariffs with Self-Selection." Bell Laboratories Economic Discussion Paper \#74, January 1977.

10. Hull, John. Options, Futures, and Other Derivative Securities. Englewood Cliffs, N.J.: Prentice Hall, 1989.

11. Klemperer, Paul, "The Competitiveness of Markets With Switching Costs." Rand Journal of Economics, Spring $1987,138-50$.

12. - "Entry Deterrence in Markets with Consumer Switching Costs." Economic Journal, Supplement to December 1987, 99-117.

13. - "Markets with Consumer Switching Costs." Quarterly Journal of Economics, May 1987, 375-394.

14. Krattenmaker, Thomas and Steven Salop, "Anticompetitive Exclusion: Raising Rivals' Costs to Achieve Power Over Price." The Yale Law Journal, December 1986, 209-94.

15. Leland, Hayne and Robert Meyer, "Monopoly Pricing Structures with Imperfect Discrimination." Bell Journal of Economics, Autumn 1976, 449-62.

16. Multichannel News, July 1, 1991, 2.

17. Rasmusen, Eric, Mark J. Ramseyer, and John Whitey, "Naked Exclusion." American Economic Review, December 1991, 1137-45.

18. Tirole, Jean. The Theory of Industrial Organization, Cambridge, Mass.: MIT Press, 1988.

19. United States Code of Federal Regulations, Title 16 Commercial Practices, Revised January 1, 1989, Office of the Federal Register, Washington, D.C., 1989.

20. Wall Street Journal, July 24, 1992, B1. 